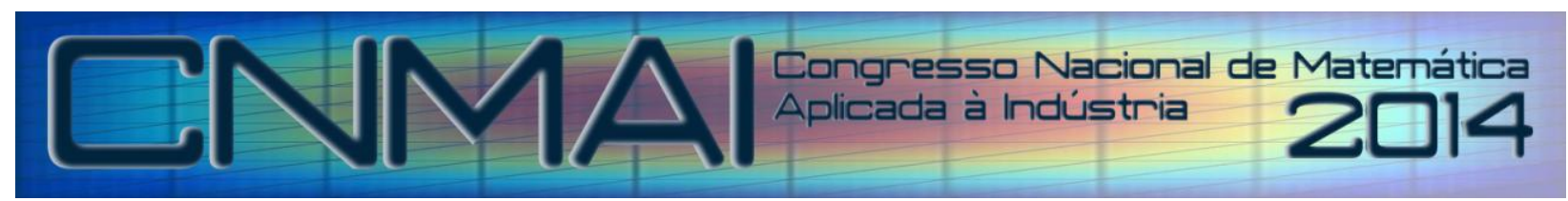

18 a 21 de novembro de 2014, Caldas Novas - Goiás

\title{
ESTIMATIVA DA ENERGIA MÉDIA GERADA EM UMA BACIA HIDROGRÁFICA ATRAVÉS DE ANÁLISES ESTATÍSTICAS
}

\author{
Jacson Hudson Inácio Ferreira, Jacson@iftm.edu.br ${ }^{1}$ \\ José Roberto Camacho, jrcamacho@ufu.br ${ }^{1}$ \\ Juliana Almansa Malagoli, juliana.malagoni@gmail.com ${ }^{1}$ \\ ${ }^{1}$ Universidade Federal de Uberlândia - Faculdade de Engenharia Elétrica. \\ Av.: João Naves de Ávila, nº 2121, Bairro: Santa Mônica, CEP: 38.408-100, Uberlândia-MG, Brasil.
}

\begin{abstract}
Resumo: A estimativa da energia média gerada é um dos aspectos relevantes analisados durante a primeira etapa do ciclo de implantação de uma pequena central geradora hidrelétrica, a Estimativa do Potencial Hidrelétrico. Neste cenário, o conhecimento da disponibilidade hídrica é parte fundamental dos estudos hidrológicos de uma bacia hidrográfica, estudos pertencentes à etapa do ciclo para determinar a vazão de um rio ou a precipitação em um local ou região, incluindo a sua variabilidade temporal. Para isso, é necessário utilizar alguns valores estatísticos que resumem, em grande parte, o comportamento hidrológico do rio ou da bacia. Neste contexto, este trabalho tem como objetivo realizar uma análise estatística para determinar os valores das variáveis que interferem no cálculo da energia média: a vazão de referência $Q_{7,10}$, a média das vazões mensais e a curva de permanência. Foi utilizado dados da série histórica de vazões de 1942 a 2013 da estação fluviométrica Ituiutaba, localizada na bacia hidrográfica do rio Tijuco em Minas Gerais. Na análise das variáveis, fez-se necessário conhecer e estudar os orgãos e legislações estaduais, um modelo probabilístico (distribuição de Weibull) e ferramentas computacionais que auxiliam a determinar os valores. Pode-se dizer que, o cálculo da estimativa da energia média gerada a partir da análise estatística da vazão para a bacia do rio Tijuco proporcionou um potencial hidrelétrico atrativo. Verificou-se também que a hidrologia estatística no processo da estimativa da energia média para empreendimentos hidrelétricos fornece dados confiáveis e que a interpretação dos dados pode amparar as tomadas de decisões na fase de projetos.
\end{abstract}

Palavras-chave: Hidrologia Estatística, Vazão, Estimativa da Energia Média

\section{INTRODUÇÃO}

Para a obtenção da autorização de um empreendimento hidrelétrico caracterizado como Pequena Central Hidrelétrica $(\mathrm{PCH})$ existem algumas etapas a serem seguidas, são elas: Estimativa do Potencial Hidrelétrico, Inventário Hidrelétrico, Viabilidade, Projeto Básico, Projeto Executivo (Faria, 2011).

$\mathrm{Na}$ etapa da Estimativa do Potencial Hidrelétrico acontece à identificação e avaliação inicial do aproveitamento de uma determinada bacia, rio, sítio, trecho, segmento ou local, obtendo assim permissão para prosseguir para a etapa seguinte. O desenvolvimento da fase de estimativa do potencial hidrelétrico, que no lato sensu o termo ganha o nome de etapa da prospecção, visa contribuir para a organização de uma estrutura de análise de cada um dos aspectos técnicos, socioambientais e econômicos que são relevantes para empreendimentos desta natureza e que podem ser avaliados de forma preliminar.

A importância desta etapa se dá ao fato de servir como um auxílio na verificação da atratividade que empresas que investem em projetos de PCH's precisam para culminar as decisões e avançar nos estudos de inventário hidrelétrico para determinada bacia hidrográfica. Como a estimativa do potencial ocorre de forma secundária, pautada em dados de agências e instituições especializadas em cada aspecto analisado durante a execução da estimativa, não há necessidade de se investir nos próximos estudos onde foi possível identificar alguma(s) objeção(ões) ou pouco propensora energeticamente e, ainda, consegue-se analisar quais os aspectos merecem mais investimentos nos estudos de campo na fase de inventário hidrelétrico (Faria, 2011).

O estudo hidrológico é uma das sessões mais importantes em qualquer etapa de projeto para uma PCH. Na etapa da Estimativa do Potencial, o conhecimento e desenvolvimento de um estudo hidrológico são responsáveis por verificar a disponibilidade hídrica, ou seja, a vazão em $\left(\mathrm{m}^{3} / \mathrm{s}\right)$, de uma bacia hidrográfica, variável esta usada para estimar a energia 
produzida em determinado ponto do rio. Eletrobrás (2000) mostra que a vazão (Q) para o local deverá ser estimada a partir de postos hidrométricos da bacia/região e que a mesma poderá ser a vazão mínima medida no local, ou $\mathrm{Q}_{95 \%}$, ou ainda a vazão média (Q') ao longo do período crítico do Sistema Interligado (jun/1949 a Nov/1956). Esses valores de vazão são encontrados após análises estatísticas da série histórica no local selecionado e utilizados para estimar a energia média produzida no local.

Diante do que foi exposto, este trabalho apresenta um estudo hidrológico da fase de estimativa do potencial hidrelétrico de uma bacia hidrográfica para a instalação de PCH's utilizando a hidrologia estatística através da série histórica de vazões de uma estação fluviométrica para determinar a vazão e apresenta a estimativa da energia média gerada usando os valores estatísticos para os cálculos.

\section{ESTUDOS HIDROLÓGICOS}

O estudo hidrológico configura-se como a sessão onde uma das variáveis para o cálculo da energia média, ou potência média, é encontrada para estimar o potencial energético de uma bacia hidrográfica para a instalação de $\mathrm{PCH}$, a vazão ou disponibilidade hídrica dada em $\left(\mathrm{m}^{3} / \mathrm{s}\right)$. As Diretrizes para Projeto de $\mathrm{PCH}$, da Eletrobrás, aplicam alguns conceitos e procedimentos para determinar a vazão. São eles:

- A vazão $(\mathrm{Q})$ para o local deverá ser estimada a partir de dados de postos hidrométricos da bacia/região;

- Deverá ser estabelecida para o local do aproveitamento uma série de vazões médias mensais derivadas de uma série histórica de um posto localizado no mesmo curso d'água ou na mesma bacia;

- Poderá efetivar a correlação direta entre áreas de drenagem de uma mesma bacia, quando limitada a diferença entre as mesmas de 3 a 4 vezes. A equação de correlação é definida pela Eq. (1) (Eletrobrás, 2000):

$$
Q_{1}=\frac{A_{1}}{A_{2}} * Q_{2}
$$

Onde:

$A_{l}=$ área de drenagem do local do aproveitamento em $\left(\mathrm{Km}^{2}\right)$;

$A_{2}=$ área de drenagem do posto existente em $\left(\mathrm{Km}^{2}\right)$;

$Q_{l}=$ vazão do local do aproveitamento em $\left(\mathrm{m}^{3} / \mathrm{s}\right)$;

$Q_{2}=$ vazão do posto existente em $\left(\mathrm{m}^{3} / \mathrm{s}\right)$;

- A série histórica deve possuir pelo menos 25 anos de registro;

- A vazão $\mathrm{Q}$ pode ser a vazão mínima medida no local, ou $\mathrm{Q}_{95 \%}$, ou ainda, a vazão média $\left(\mathrm{Q}^{\prime}\right)$ ao longo do período crítico do Sistema Interligado (jun/1949 a nov/1956).

Faria (2011) afirma que, sempre que possível, na etapa de prospecção devem ser utilizados estudos hidrológicos existentes, calcados em dados de postos fluviométricos devidamente avaliados, quanto à sua qualidade e quantidade, para a estimativa da disponibilidade hídrica de uma seção de um curso d'água. Entretanto, uma rede de postos fluviométricos, ainda que densa, dificilmente atenderá com seus dados a todos os locais de interesse. Que nesse contexto, os estudos de regionalização de vazões podem ser considerados uma alternativa adequada para estimativa da disponibilidade hídrica.

Ainda de acordo com Faria (2011), o estudo de regionalização de vazões compreende espacializar a informação hidrológica, normalmente pontual, possibilitando a transferência de informações de uma região para a outra dentro de uma área com comportamento hidrológico semelhante. A regionalização hidrológica envolve a determinação de variáveis em diferentes locais da região e é definida por limites geográficos, levando em consideração os limites de bacias hidrográficas. A variável regionalizada é estimada através de uma função de variáveis explicativas. Um exemplo adotado foi determinar valores de vazão através da precipitação média anual e área de drenagem, de acordo com a regionalização de vazões do Atlas Digital das Águas de Minas, elaborado pelo Instituto Mineiro de Águas - IGAM, Fundação Rural Minas e Universidade de Viçosa.

Porém, Eletrobrás (2000) recomenda a elaboração de um estudo de regionalização de vazões caso a diferença entre a área de estudo para a área do posto hidrométrico seja 4 vezes maior. A consistência, ou não, dos dados de postos fluviométricos não deve ser o fator decisivo quanto à confiabilidade de seus resultados. Os fenômenos da natureza não são cabíveis de serem expressos de forma igualitária no decorrer dos anos e como eles acontecem, porém a análise dos dados de postos fluviométricos para a determinação da disponibilidade hídrica permite uma melhor compreensão do que ocorreu ao longo dos anos na bacia, verificando a sua potencialidade através dos dados disponíveis e podendo até estimar suas perspectivas para os anos seguintes, de forma secundária visto que se trata de um fenômeno da natureza.

Segundo a Agência Nacional das Águas - ANA, existem 4.543 estações de monitoramento, estrategicamente localizadas nas várias bacias hidrográficas brasileiras, que é possível mensurar volumes de chuvas, a evaporação da água, o nível e a vazão dos rios, a quantidade de sedimentos e a qualidade das águas em estações respectivamente relacionadas: pluviométricas, evaporimétricas, fluviométricas, sedimentrométricas e da qualidade da água.

Dessa forma, a aplicação do estudo hidrológico a partir de séries históricas de vazões de uma bacia/rio, para esta etapa inicial para determinar as possíveis vazões de projeto, configura-se como um bom método a ser aplicado durante essa fase inicial devido ao grande número de estações existentes com os dados de vazões e foi o método utilizado neste 
trabalho. Após ser realizado o estudo, poderá ser feita a correlação entre as áreas de drenagem, respeitando o limite de diferença entre as mesmas, como citado anteriormente.

\subsection{Direitos de Uso dos Recursos Hídricos}

Todo e qualquer empreendimento que utilize ou afete os recursos hídricos está sujeito à legislação. A Agência Nacional de Águas (ANA) é o órgão federal responsável pelos recursos hídricos e tem como missão programar e coordenar a gestão compartilhada e integrada dos recursos hídricos e regular o acesso à água, promovendo o uso sustentável em benefício das atuais e futuras gerações.

Os estudos hidrológicos precisam associar, durante a sua realização, aos aspectos legislativos de utilização dos recursos hídricos que os órgãos ambientais, nos níveis estaduais e federais, fixam para o uso nos procedimentos administrativos de licenciamento ambiental, concessão de outorga de água e construção de barragens. É importante nos estudos hidrológicos o conhecimento da legislação vigente do órgão federal, ANA, e também dos órgãos estaduais onde o empreendimento poderá se localizar.

\subsection{Hidrologia Estatística}

O conhecimento da disponibilidade hídrica é parte fundamental dos estudos hidrológicos de uma bacia hidrográfica, estudos estes pertencentes a etapa de estimativa do potencial hidrelétrico para determinar a vazão do rio ou a precipitação em um local ou região, incluindo a sua variabilidade temporal (Collischonn et al., 2008). Por isso, é necessário utilizar alguns valores estatísticos que resumem, em grande parte, o comportamento hidrológico do rio ou da bacia. Neste contexto, faz-se necessário realizar uma análise estatística para determinar os valores das vazões de referência, vazões médias, vazões máximas e vazões mínimas, valores que podem entrar no cálculo do potencial energético (energia média).

Conforme descrito no início, as vazões de referência para os projetos de PCH são vazão mínina medida no local, ou $\mathrm{Q}_{95 \%}$ (vazão que é superada em $95 \%$ do tempo estudado), ou ainda, a vazão média (Q') ao longo do período crítico do sisterma interligado (jun/1949 a nov/1956). Estes valores de vazão são encontrados após análises estatísticas da série histórica no local selecionado. Com as perspectivas relatadas, as análises compreenderam e demonstraram os cálculos das seguintes variáveis estatísticas:

a) Média das Vazões: A vazão ou precipitação média é a média de toda a série de vazões ou precipitações registradas, e é muito importante na avaliação da disponibilidade hídrica total de uma bacia. As vazões médias mensais representam o valor médio da vazão para cada mês do ano, e são importantes para analisar a sazonalidade de um rio (Collischonn et al., 2008).

A média das vazões foi encontrada através da Eq. (2) (Collischonn et al., 2008):

$$
\text { Qmed }=\frac{\sum_{i=1}^{n} Q i}{n}
$$

Onde: $Q_{m e d}$ é a vazão média (diária, mensal ou anual) e $n$ é o número de dados disponíveis (diários, mensais ou anuais).

b) Curva de Permanência: A curva de permanência relaciona a vazão ou nível d'água de um rio com a sua probabilidade de ocorrerem valores iguais ou superiores, como exemplo, a vazão $\mathrm{Q}_{95 \%}$. Ela pode ser estabelecida com base em valores diários, semanais ou mensais para todo o período da série histórica disponível, ou ainda, se necessário, para cada mês do ano. A sua elaboração é uma das analíses estatíticas mais importante na hidrologia e para empreendimentos hidrelétricos. A curva de permanência auxilia na análise dos dados de vazão determinando a constância de seus valores, porcentagem do tempo em que o rio apresenta vazões em determinada faixa (Eletrobrás, 2000).

Em projetos hidrelétricos a curva de permanência pode ser utilizada para determinação da potência a ser instalada e para estudos preliminares onde a regionalização das vazões é importante. Os cálculos para a construção da curva envolvem variáveis de frequência (relativa e absoluta) e amplitude dos valores de vazões de série históricas de um rio. E também, é possível utilizar ferramentas computacionais que agilizam o trabalho e possuem a mesma confiabilidade para preparar a curva de permanênia.

Para o cálculo da curva de permanênica, o software HIDRO, fornecido pela Agência Nacional de Águas (ANA) e uma função do OpenOffice Calc chamada PERCENTIL são dois exemplos de ferramentas computacionais que agilizam o processo e gera o gráfico da curva de permanência.

Este trabalho utilizou, pela simplicidade de uso, a função PERCENTIL do OpenOffice Calc. Para a construção da curva utilizando o Percentil é necessário:

- $\quad$ Em uma coluna, inserir valores de duração, D, entre 0 e 1 . (Ex: $0 ; 0,05 ; 0,1 ; 0,15 ; \ldots ; 1)$;

- $\quad$ Para cada valor de duração, calcule a vazão equivalente usando a função = PERCENTIL (MATRIZ; 1- D);

- MATRIZ (M) é o conjunto de células onde se encontra a série de dados, organizadas em séries diárias, semanais ou mensais, e D é a duração.

- $\quad$ Fazer o gráfico Vazão/Probabilidade. 
c) Vazão de Sete Dias com Período de Recorrência de Dez Anos $\left(\mathrm{Q}_{7,10}\right)$ : A vazão $\mathrm{Q}_{7,10}$, ou seja, a vazão mínima média anual de 7 dias $\left(\mathrm{Q}_{7}\right)$ de duração com período de retorno de 10 anos, é utilizada em alguns estados brasileiros como vazão de referência para outorga do uso dos recursos hídricos superficiais (Reis, 2007).

Para este estudo foi aplicado a função de distribuição de Weibull por ser considerado como um dos parâmetros de distribuições mais comuns usados no cálculo de vazões mínimas de rios (Sarmento, 2007; Reis 2007 e Santos et al. 2011). A praticidade dos cálculos a serem executados também foi levado em consideração. Para utilizar o ajuste de vazão pela distruibuição de Weibull, efetuou-se o cálculo da média e do desvio padrão dos valores de $\mathrm{Q}_{7}$. Em seguida determinou-se o coeficiente de variação $(C V)$ conforme a Eq. (3) (Santos et al. 2011):

$$
C V=\frac{\text { desvio padrão }}{\text { média } Q 7}
$$

Logo depois, calculou-se os parâmetros da distribuição de Weibull $\alpha, A(\alpha)$ e $\beta$, utilizando as Eq. (4), (5) e (6) (Santos et al. 2011):

$$
\begin{gathered}
\alpha=1,0122 \cdot C V^{-1,077} \\
A(\alpha)=0,9982-0,4419 * C V+0,4360 * C V^{2} \\
\beta=(\text { média } Q 7) / A(\alpha)
\end{gathered}
$$
2011):

A vazão mínima para o tempo de retorno $(T r)$ desejado $\left(Q_{7,10}\right)$ foi calculada por meio da Eq. (7) (Santos et al.

$$
Q_{7,10}=\beta\left[-\ln \left(1-\frac{1}{T r}\right)\right]^{1 / \alpha}
$$

\subsection{Vazão Ecológica}

Aliado ao fator ambiental, durante os estudos hidrológicos é preciso identificar qual a Vazão Ecológica necessária para a preservação das características locais já existentes na bacia em estudo, seja pela agricultura, abastecimento público, industrial, etc.

Vazão Ecológica ou Residual é a demanda necessária de água a manter em um rio de forma a assegurar a manutenção e conservação dos ecossistemas aquáticos naturais, aspectos da paisagem de outros de interesse científico ou cultural. É um valor de referência que deve ser mantido no trecho de um rio a jusante de um barramento ou de uma retirada de água. Em geral, a fixação de vazões ecológicas no Brasil tem sido feita principalmente através da legislação nos níveis estadual e federal, principalmente para uso nos procedimentos administrativos de licenciamento ambiental e concessão de outorga de água e construção de barragens. Diante disso, se faz necessário conhecer os órgãos ambientais responsáveis pelos recursos hídricos e as legislações do(s) Estado(s) que a bacia do rio se encontra, como dito anteriormente (Sarmento, 2007).

\section{ESTIMATIVA NA ENERGIA MÉDIA GERADA}

A avaliação do potencial hidroenergético de um aproveitamento considera duas variáveis como relevante, queda líquida e vazão, conforme a Eq. (8) (Eletrobrás, 2000):

$$
P_{e f}=9,81 * \eta * Q * H l i q
$$

Onde:

$P_{e f}=$ Potência efetiva (KW).

$\eta=$ Rendimento do conjunto turbina-gerador.

$Q=\operatorname{Vazão}\left(\mathrm{m}^{3} / \mathrm{s}\right)$.

$H_{l i q}=$ Queda liquida (m).

Durante a fase de prospecção do local é feita a estimativa da energia média (ou potência média) que pode ser produzida no aproveitamento, aspecto este relevante nesta etapa. Geralmente, essa estimativa é feita com base nas séries históricas de vazões definidas nos estudos hidrológicos para o local do aproveitamento e da queda líquida, definida a partir da percepção do arranjo da usina (nível do reservatório, canal de fuga, circuito de adução, etc).

Para este trabalho foi aplicado um estudo para a estimativa da potência média de um aproveitamento de forma preliminar. As variáveis utilizadas para os cálculos, vazão e queda líquida, foram separadas e considerou-se apenas a vazão para o cálculo, sendo a potência média estimada com base na variação dos valores de vazão e de acordo com a curva de rendimento de turbinas hidráulicas. A curva de rendimento de turbinas hidráulicas leva em consideração a 
variação dos valores de vazão (vazão turbinável/vazão máxima) com queda constante. Consequentemente, a potência média se torna uma variável em função da queda.

Sendo assim, o cálculo utilizado é descrito na Eq. (9):

$$
P_{\text {med }}=9,81 * \eta *\left(Q-Q_{\text {eco }}\right)
$$

Onde:

$P_{\text {med }}=$ Potência média correspondente à energia média gerada $(\mathrm{KWmédio/m})$.

$Q=$ vazão $\mathrm{média}\left(\mathrm{m}^{3} / \mathrm{s}\right)$.

$Q_{\text {eco }}=$ vazão ecológica $\left(\mathrm{m}^{3} / \mathrm{s}\right)$.

$\eta=$ rendimento da turbina.

Optou-se por essa separação das variáveis para a potência média porque os arranjos que são definidos nessa fase de prospecção são representativos, ou seja, apresenta características básicas. E como nesta fase busca-se observar a atratividade, a análise da potência média em etapas faz com que primeiro verifique qual a potencialidade energética do local, independente do arranjo da usina, utilizando apenas a disponibilidade hídrica do local, objeto de estudo deste trabalho, e após isso, se analise o tipo de estrutura, reservatório, operação da usina para identificar a real estimativa da potência média do local.

\section{MATERIAL E MÉTODOS}

Para aplicação da hidrologia estatística para determinar a vazão de uma bacia hidrográfica e a estimativa da energia média gerada para uma PCH foi escolhida a bacia do rio Tijuco limitado ao município de Ituiutaba - MG. A escolha pelo local de aplicação da metodologia foi motivada por ser uma região que já possui PCH's implantadas, em construção ou que precisam de autorização para entrar em funcionamento. Em 11 de maio de 2006 a ANEEL - Agência Nacional de Energia Elétrica aprovou por meio do Despacho n. 950, os Estudos de Inventário Hidrelétrico Simplificado do rio Tijuco, quando foram considerados treze aproveitamentos hidrelétricos com capacidade total de 170,8 MW, sendo que 6 estão localizadas no município de Ituiutaba - MG. A usina Salto Morais, com 2,39 MW e com concessão outorgada à CEMIG, encontra-se em operação nacional.

A bacia hidrográfica do Rio Tijuco, município de Ituiutaba - MG, com área aproximada de $1.335,1 \mathrm{~km}^{2}$, região de grande significado econômico para o Estado de Minas Gerais, localiza-se no Triângulo Mineiro, entre as coordenadas geográficas $18^{\circ} 40^{\prime}$ e $19^{\circ} 47^{\prime} \mathrm{S}$ e $47^{\circ} 53^{\prime}$ a $50^{\circ} 13^{\prime} \mathrm{W}$. O rio Tijuco nasce a $950 \mathrm{~m}$ de altitude, nas coordenadas $19^{\circ}$ 31'39.88" S; 47054'41.40' W, no município de Uberaba-MG, e tem sua foz na cota de $526 \mathrm{~m}$, sendo afluente da margem esquerda do Rio Paranaíba, tendo como principais afluentes os rios Prata, Babilônia, Cabaçal, Douradinho, Panga, dentre outros (Junior et al. (2010).

De acordo com o Sistema Nacional de Informações sobre os Recursos Hídricos (SNIRH), coordenado pela Agência Nacional de Águas, dentro do município de Ituiutaba-MG existem duas estações de monitoramento dos recursos hidrícos para o rio Tijuco. Para este trabalho foi escolhida a estação Ituiutaba por possuir dados das séries históricas de vazão dos últimos 72 anos, 1942 a 2013. A estação Ituiutaba está localizada nas coordenadas 1856' e 49²6', altitude $563 \mathrm{~m}$ e área de drenagem de $6310 \mathrm{Km}^{2}$.

Os dados das séries históricas de vazão foi disponiblizado pela Agência Nacional de Águas, atráves do Serviço de Informação ao Cidadão - SIC, e também pelo Sistema Nacional de Informações sobre os Recursos Hídricos (SNIRH). Foi observado que para alguns anos havia a falta de dados registrados em certos períodos, mas que não compromete a veracidade dos cálculos por se tratar de uma porcentagem pequena, aproximadamente $1 \%$, em comparação a número de dados registrados.

A bacia hidrográfica em estudo localiza-se no Estado de Minas Gerais. No Estado, o IGAM (Instituto Mineiro de Gestão das Águas) é responsável por planejar e promover ações direcionadas à preservação da quantidade e da qualidade das águas de Minas Gerais. O gerenciamento é feito por meio da outorga de direito de uso da água, do monitoramento da qualidade das águas superficiais e subterrâneas do Estado, dos planos de recursos hídricos, bem como da consolidação de Comitês de Bacias Hidrográficas (CBHs) e Agências de Bacia. O Instituto tem como diretriz uma administração compartilhada e descentralizada, envolvendo todos os segmentos sociais. Fez-se então necessário conhecer as legislações do IGAM para os cálculos realizados. As principais serão destacadas durante a execução dos mesmos.

De posse da série histórica de vazões da estação Ituiutaba procedeu-se os cálculos para determinar a vazão média, a curva de permanência, a vazão $\mathrm{Q}_{7,10}$ e posteriormente, estimado a energia média do rio Tijuco no município de Ituiutaba - MG com base no rendimento das turbinas e as variações de vazão ao longo do ano. Para determinar a vazão média utilizou-se a função MÉDIA; para a curva de permanência utilizou-se o PERCENTIL e para a vazão miníma de recorrência de sete dias $\left(\mathrm{Q}_{7}\right)$ utilizou-se a análise de dados MÉDIA MÓVEL, todos função do OpenOffice Calc.

\section{RESULTADOS E DISCUSSÕES}

A partir dos dados históricos da estação Ituiutaba foi calculado a vazão média mensal a fim de representar o mínimo esperado de volume de água em um ano médio. A Tabela 1 apresenta a média da vazão mensal global do rio Tijuco a partir da estação Ituiutaba, de 1942 a 2013. 
Tabela 1. Média das vazões mensais do rio Tijuco, estação Ituiutaba

\begin{tabular}{|c|c|c|c|c|c|}
\hline Mês & Vazão $\left(\mathbf{m}^{\mathbf{3}} / \mathbf{s}\right)$ & Mês & Vazão $\left(\mathbf{m}^{\mathbf{3}} / \mathbf{s}\right)$ & Mês & Vazão $\left(\mathbf{m}^{\mathbf{3}} \mathbf{s} \mathbf{s}\right)$ \\
\hline Janeiro & 160,8508 & Maio & 75,9235 & Setembro & 40,2699 \\
\hline Fevereiro & 164,1751 & Junho & 60,9954 & Outubro & 56,2166 \\
\hline Março & 149,7311 & Julho & 51,7608 & Novembro & 78,9305 \\
\hline Abril & 113,1393 & Agosto & 42,3645 & Dezembro & 125,0129 \\
\hline
\end{tabular}

Observa-se na Tabela 1 que as maiores vazões ocorrem em Fevereiro e as menores em Setembro, consequência direta da sazonalidade das chuvas, que ocorrem de forma concentrada no verão (Dez a Fev). É possível também destacar que a vazão média de longo termo $\left(Q_{m e d}\right)$ é de $\mathbf{9 3 , 2 8 0 9}\left(\mathbf{m}^{3} / \mathbf{s}\right)$. Calculou-se também, pela média, a vazão média do período critico do Sistema Interligado. Esse período está no intervalo entre Jun/1949 a Nov/1956. Sendo assim, a média do período crítico é $\mathbf{4 4 , 6 7 5 1}\left(\mathrm{m}^{3} / \mathrm{s}\right)$.

A curva de permanência foi construída conforme a média das vazões mensais, apresentadas na Tab. 1. Organizouse a matriz $\mathrm{M}$ de acordo com as médias de cada mês para todos os anos devido ao extenso número de dados.

Logo em seguida, utilizou-se a função PERCENTIL para encontrar os dados necessários para a construção da curva. Os valores encontrados para cada período de duração D se encontram na Tab. 2. A Figura 1 apresenta o gráfico da curva de permanência encontrada para o rio Tijuco.

Tabela 2. Valores de vazão com sua respectiva probabilidade de ocorrer no decorrer do tempo

\begin{tabular}{|c|c|c|c|}
\hline Duração (D) & Vazão $\left.\mathbf{~ m}^{3} / \mathbf{s}\right)$ & Duração (D) & Vazão (m $\mathbf{3} / \mathbf{s})$ \\
\hline $0 \%$ & 164,1751 & $5 \%$ & 162,3467 \\
\hline $10 \%$ & 159,7389 & $15 \%$ & 153,623 \\
\hline $20 \%$ & 144,7875 & $25 \%$ & 131,1924 \\
\hline $30 \%$ & 121,4508 & $35 \%$ & 114,9203 \\
\hline $40 \%$ & 99,45579 & $45 \%$ & 80,64096 \\
\hline $50 \%$ & 77,42699 & $55 \%$ & 75,17706 \\
\hline $60 \%$ & 66,96663 & $65 \%$ & 60,27859 \\
\hline $70 \%$ & 57,65024 & $75 \%$ & 55,10263 \\
\hline $80 \%$ & 52,65192 & $85 \%$ & 48,47205 \\
\hline $90 \%$ & 43,3041 & $95 \%$ & 41,4219 \\
\hline $100 \%$ & 40,26987 & & \\
\hline
\end{tabular}

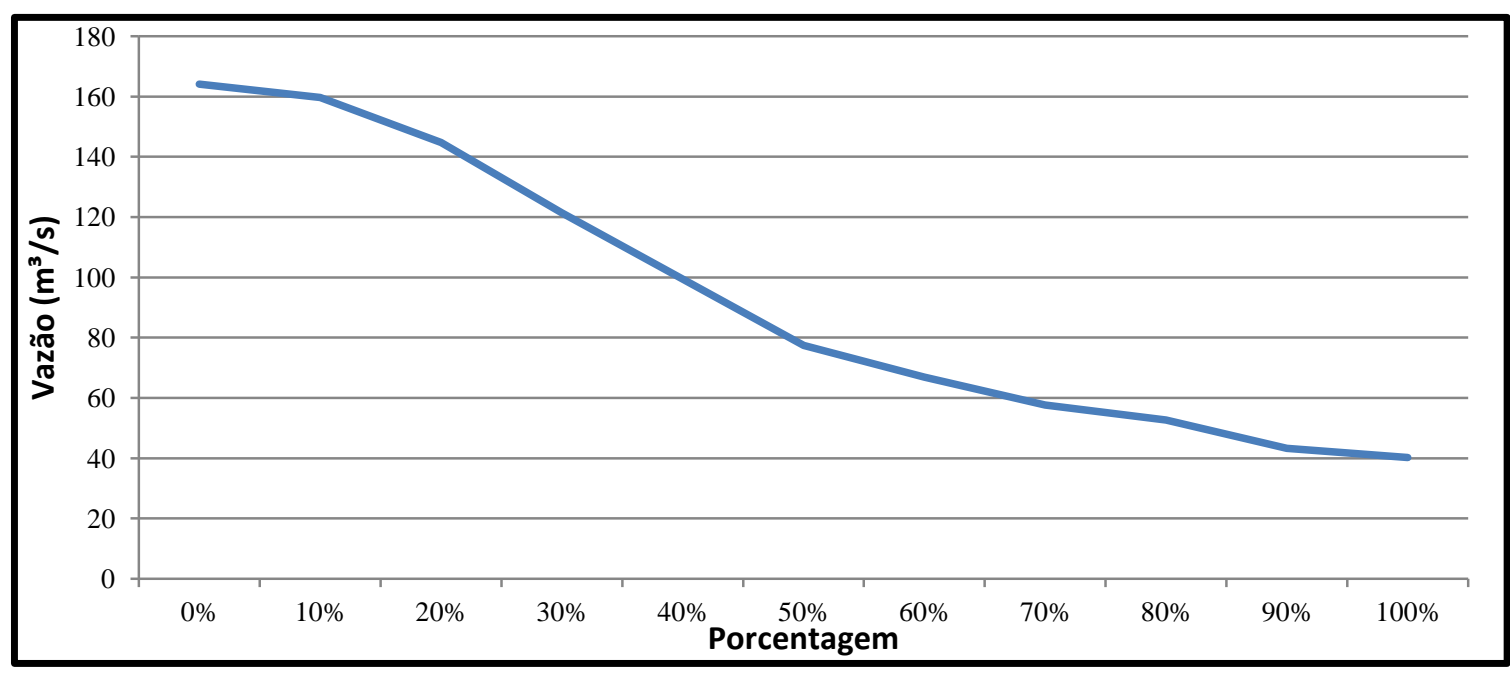

Figura 1. Curva de permanência rio Tijuco

Alguns pontos da curva de permanência recebem maior atenção. Como o intuito do estudo é para fins hidrelétricos, o ponto de maior destaque é para a vazão $Q_{95 \%}$, que possui um valor de $\mathbf{4 1 , 4 2 2}\left(\mathbf{m}^{3} / \mathbf{s}\right)$. Este valor de vazão pode ser o utilizado para definir a energia assegurada em um aproveitamento hidrelétrico.

Os valores das menores médias móveis de sete dias consecutivos $\mathrm{Q}_{7}$ encontrados para cada ano da série estudada podem ser observados na Tab. 3 . 
Tabela 3. Menores valores das médias movéis de sete dias

\begin{tabular}{|c|c|c|c|c|c|c|c|c|c|c|c|}
\hline Ano & $\begin{array}{c}\mathrm{Q}_{7} \\
\left(\mathrm{~m}^{3} / \mathrm{s}\right)\end{array}$ & Ano & $\begin{array}{c}\mathrm{Q}_{7} \\
\left(\mathrm{~m}^{3} / \mathrm{s}\right)\end{array}$ & Ano & $\begin{array}{c}\mathrm{Q}_{7} \\
\left(\mathrm{~m}^{3} / \mathrm{s}\right)\end{array}$ & Ano & $\begin{array}{c}\mathrm{Q}_{7} \\
\left(\mathrm{~m}^{3} / \mathrm{s}\right)\end{array}$ & Ano & $\begin{array}{c}\mathrm{Q}_{7} \\
\left(\mathrm{~m}^{3} / \mathrm{s}\right)\end{array}$ & Ano & $\begin{array}{c}\mathrm{Q}_{7} \\
\left(\mathrm{~m}^{3} / \mathrm{s}\right)\end{array}$ \\
\hline $\mathbf{1 9 4 2}$ & 31,5 & $\mathbf{1 9 5 4}$ & 9,6 & $\mathbf{1 9 6 6}$ & 33,542 & $\mathbf{1 9 7 8}$ & 28,514 & $\mathbf{1 9 9 0}$ & 37,8 & $\mathbf{2 0 0 2}$ & 15,023 \\
\hline $\mathbf{1 9 4 3}$ & 31,614 & $\mathbf{1 9 5 5}$ & 6,0286 & $\mathbf{1 9 6 7}$ & 36,571 & $\mathbf{1 9 7 9}$ & 33,642 & $\mathbf{1 9 9 1}$ & 43,514 & $\mathbf{2 0 0 3}$ & 31,777 \\
\hline $\mathbf{1 9 4 4}$ & 30,414 & $\mathbf{1 9 5 6}$ & 18,929 & $\mathbf{1 9 6 8}$ & 32,128 & $\mathbf{1 9 8 0}$ & 52 & $\mathbf{1 9 9 2}$ & 43,085 & $\mathbf{2 0 0 4}$ & 20,511 \\
\hline $\mathbf{1 9 4 5}$ & $\#$ & $\mathbf{1 9 5 7}$ & 22,5286 & $\mathbf{1 9 6 9}$ & 18,928 & $\mathbf{1 9 8 1}$ & 22,2 & $\mathbf{1 9 9 3}$ & 51,785 & $\mathbf{2 0 0 5}$ & 28,669 \\
\hline $\mathbf{1 9 4 6}$ & $\#$ & $\mathbf{1 9 5 8}$ & 34,4 & $\mathbf{1 9 7 0}$ & 25,5 & $\mathbf{1 9 8 2}$ & 51,985 & $\mathbf{1 9 9 4}$ & 40,4 & $\mathbf{2 0 0 6}$ & 42,591 \\
\hline $\mathbf{1 9 4 7}$ & $\#$ & $\mathbf{1 9 5 9}$ & 28,7 & $\mathbf{1 9 7 1}$ & 7,405 & $\mathbf{1 9 8 3}$ & 49,628 & $\mathbf{1 9 9 5}$ & 38,7 & $\mathbf{2 0 0 7}$ & 26,199 \\
\hline $\mathbf{1 9 4 8}$ & 29,042 & $\mathbf{1 9 6 0}$ & 21,3 & $\mathbf{1 9 7 2}$ & 28,014 & $\mathbf{1 9 8 4}$ & 46,471 & $\mathbf{1 9 9 6}$ & 34,198 & $\mathbf{2 0 0 8}$ & 27,997 \\
\hline $\mathbf{1 9 4 9}$ & 20,128 & $\mathbf{1 9 6 1}$ & 19,1 & $\mathbf{1 9 7 3}$ & 28,871 & $\mathbf{1 9 8 5}$ & 40,228 & $\mathbf{1 9 9 7}$ & 33,703 & $\mathbf{2 0 0 9}$ & 51,135 \\
\hline $\mathbf{1 9 5 0}$ & 19,442 & $\mathbf{1 9 6 2}$ & 23,214 & $\mathbf{1 9 7 4}$ & 29,1 & $\mathbf{1 9 8 6}$ & 33,428 & $\mathbf{1 9 9 8}$ & 30,115 & $\mathbf{2 0 1 0}$ & 29,136 \\
\hline $\mathbf{1 9 5 1}$ & 23,9 & $\mathbf{1 9 6 3}$ & 15,6 & $\mathbf{1 9 7 5}$ & 53,5 & $\mathbf{1 9 8 7}$ & 41,428 & $\mathbf{1 9 9 9}$ & 28,311 & $\mathbf{2 0 1 1}$ & 3,645 \\
\hline $\mathbf{1 9 5 2}$ & 21,5 & $\mathbf{1 9 6 4}$ & $\#$ & $\mathbf{1 9 7 6}$ & 35,185 & $\mathbf{1 9 8 8}$ & 37,586 & $\mathbf{2 0 0 0}$ & 25,504 & $\mathbf{2 0 1 2}$ & 29,96 \\
\hline $\mathbf{1 9 5 3}$ & 20,128 & $\mathbf{1 9 6 5}$ & $\#$ & $\mathbf{1 9 7 7}$ & 38,1 & $\mathbf{1 9 8 9}$ & 35,928 & $\mathbf{2 0 0 1}$ & 22,301 & $\mathbf{2 0 1 3}$ & 32,511 \\
\hline
\end{tabular}

Alguns anos não apresentam seus valores devido ao pouco número de dados registrados para aquele ano, citado anteriormente. Optou-se pela exclusão desses anos para que não favorecesse ou prejudicasse os cálculos executados.

$\mathrm{O}$ valor da vazão $\mathrm{Q}_{7,10}$ e das variáveis envolvidas no seu cálculo encontram-se na Tab. 4.

Tab. 4. Vazão $Q_{7,10}$ e suas variáveis

\begin{tabular}{|c|c|c|}
\hline Média $\mathbf{Q}_{7}$ & Desvio Padrão $\mathbf{Q}_{7}$ & $\mathbf{C V}$ \\
\hline $30,5297\left(\mathrm{~m}^{3} / \mathrm{s}\right)$ & 11,2475 & 0,3684 \\
\hline $\boldsymbol{\alpha}$ & $\mathbf{A}(\boldsymbol{\alpha})$ & $\boldsymbol{\beta}$ \\
\hline 2,9672 & 0,8946 & 34,1266 \\
\hline \multicolumn{3}{|c|}{} \\
\hline \multicolumn{3}{|c|}{ Vazão $\mathbf{Q}_{7,10}$} \\
\hline
\end{tabular}

A Portaria IGAM n $n^{\circ} 49$, de 01 de julho de 2010 , Artigo $5^{\circ}, \S 1^{\circ}$ garante a jusante de cada derivação, fluxos residuais minimos equivalentes a $70 \%$ da $\mathrm{Q}_{7,10}$. Sendo assim, a vazão ecológica, se fosse construido um empreendimento em derivação nessa localidade, seria de 11,2 ( $\left.\mathbf{m}^{3} / \mathbf{s}\right)$.

Para a estimativa da energia gerada, primeiramente foi determinado a vazão turbinável, em ( $\left.\mathrm{m}^{3} / \mathrm{s}\right)$, após subtrair a vazão ecológica das vazões médias mensais. Os valores se encontram na Tab. 5.

Tab. 5. Vazão Média Mensal, Ecológica e Turbinável

\begin{tabular}{|l|c|c|c|}
\cline { 2 - 4 } \multicolumn{1}{c|}{} & $\begin{array}{c}\text { Vazão Média Mensal } \\
\left(\mathrm{m}^{3} / \mathrm{s}\right)\end{array}$ & $\begin{array}{c}\text { Vazão Ecologica } \\
\left(\mathrm{m}^{3} / \mathrm{s}\right)\end{array}$ & $\begin{array}{c}\text { Vazão Turbinável } \\
\left(\mathrm{m}^{3} / \mathrm{s}\right)\end{array}$ \\
\hline Janeiro & 160,8508 & 11,19 & 149,6608 \\
\hline Fevereio & 164,1751 & 11,19 & 152,9851 \\
\hline Março & 149,7311 & 11,19 & 138,5411 \\
\hline Abril & 113,1393 & 11,19 & 101,9493 \\
\hline Maio & 75,9235 & 11,19 & 64,7335 \\
\hline Junho & 60,9954 & 11,19 & 49,8054 \\
\hline Julho & 51,7608 & 11,19 & 40,5708 \\
\hline Agosto & 42,3645 & 11,19 & 31,1745 \\
\hline Setembro & 40,2699 & 11,19 & 29,0799 \\
\hline Outubro & 56,2166 & 11,19 & 45,0266 \\
\hline Novembro & 78,9305 & 11,19 & 67,7405 \\
\hline Dezembro & 125,0129 & 11,19 & 113,8229 \\
\hline
\end{tabular}

Logo após foi escolhido alguns valores de vazão, entre o intervalo de $\mathrm{Q}_{95 \%}, 41,422\left(\mathrm{~m}^{3} / \mathrm{s}\right)$ até $Q_{m e d}, 92,2809\left(\mathrm{~m}^{3} / \mathrm{s}\right)$, para identificar qual acarretaria em uma melhor estimativa de energia. Quando a vazão escolhida fosse menor que as vazões médias mensais, prevaleceria a escolhida. Caso contrário, utilizaria a vazão média mensal. A Tabela 6 apresenta as vazões mensais aplicadas, para cada mês, após fazer essa relação.

Tab. 6. Vazões Mensais Aplicadas 


\begin{tabular}{|c|c|c|c|c|}
\cline { 2 - 5 } \multicolumn{1}{c|}{} & $\mathrm{Q}_{45}\left(\mathrm{~m}^{3} / \mathrm{s}\right)$ & $\mathrm{Q}_{60}\left(\mathrm{~m}^{3} / \mathrm{s}\right)$ & $\mathrm{Q}_{75}\left(\mathrm{~m}^{3} / \mathrm{s}\right)$ & $\mathrm{Q}_{90}\left(\mathrm{~m}^{3} / \mathrm{s}\right)$ \\
\hline Janeiro & 45 & 60 & 75 & 90 \\
\hline Fevereio & 45 & 60 & 75 & 90 \\
\hline Março & 45 & 60 & 75 & 90 \\
\hline Abril & 45 & 60 & 75 & 90 \\
\hline Maio & 45 & 60 & 64,7335 & 64,7335 \\
\hline Junho & 45 & 49,8054 & 49,8054 & 49,8054 \\
\hline Julho & 40,5708 & 40,5708 & 40,5708 & 40,5708 \\
\hline Agosto & 31,1745 & 31,1745 & 31,1745 & 31,1745 \\
\hline Setembro & 29,0799 & 29,0799 & 29,0799 & 29,0799 \\
\hline Outubro & 45 & 45,0266 & 45,0266 & 45,0266 \\
\hline Novembro & 45 & 60 & 67,7405 & 67,7405 \\
\hline Dezembro & 45 & 60 & 75 & 90 \\
\hline
\end{tabular}

Foi utilizado o rendimento da turbina Francis para fins de cálculo, apresentados na Fig. 2.

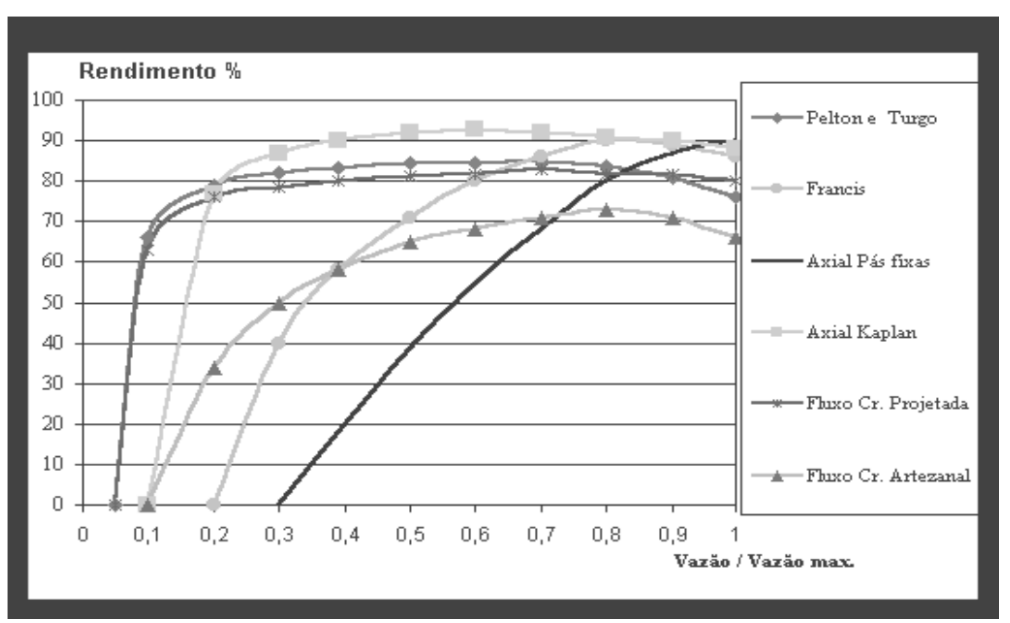

Fig. 2. Gráfico dos rendimentos de alguns tipos de turbinas com variação de vazões e queda constante. Fonte: Miranda (2009)

Escolheu-se nos cálculos da potência média para a turbina tipo Francis rendimentos igual ou maiores que 0,87. Tal valor é o resultado da relação Vazão/Vazão max igual a 1, apresentados na Fig. 2. Para determinar o rendimento primeiro fez-se a divisão entre a vazão mensal aplicada pela vazão turbinável. Depois de encontrado o valor, observa-se na curva da turbina escolhida, o valor correspondente ao rendimento.

Após encontrado todas as variáveis, fez-se a estimativa da energia média gerada e obteve os seguintes valores de potências médias (KW/m) que são apresentados na Tab. 7

Tab. 7. Potência média (KW/m) para a turbina tipo Francis

\begin{tabular}{|c|c|c|c|c|}
\cline { 2 - 5 } \multicolumn{1}{c|}{} & $\mathrm{P}_{45}$ & $\mathrm{P}_{60}$ & $\mathrm{P}_{75}$ & $\mathrm{P}_{90}$ \\
\hline Janeiro & 383,67 & 511,56 & 639,45 & 767,34 \\
\hline Fevereio & 383,67 & 511,56 & 639,45 & 767,34 \\
\hline Março & 383,67 & 511,56 & 639,45 & 767,34 \\
\hline Abril & 383,67 & 511,56 & 639,45 & 767,34 \\
\hline Maio & 383,67 & 511,56 & 570,9495 & 0 \\
\hline Junho & 383,67 & 439,2836 & 0 & 0 \\
\hline Julho & 353,8585 & 0 & 0 & 0 \\
\hline Agosto & 265,7938 & 0 & 0 & 0 \\
\hline Setembro & 0 & 0 & 0 & 0 \\
\hline Outubro & 383,67 & 392,722 & 0 & 0 \\
\hline Novembro & 383,67 & 511,56 & 590,8326 & 0 \\
\hline Dezembro & 383,67 & 511,56 & 639,45 & 767,34 \\
\hline Total & $\mathbf{4 0 7 2 , 6 8 2}$ & $\mathbf{4 4 1 2 , 9 2 6}$ & $\mathbf{4 3 5 9 , 0 3 2}$ & $\mathbf{3 8 3 6 , 7}$ \\
\hline
\end{tabular}


A Tabela 7 proporciona as seguintes observações:

a) Nota-se que a potência é nula para alguns meses. Isso ocorre por conta da relação vazão/vazão máxima imprimir um rendimento menor que aqueles escolhido para a turbina $(\geq 0,87)$. Sendo assim, a não utilização do mesmo para fins de cálculo.

b) Os resultados da Tab. 7 e a Fig. 2 mostram que, a medida que a relação vazão/vazão máxima diminui, ocorre um decréscimo do rendimento na turbina Francis, gerando menores potências médias para as vazões escolhidas.

c) De acordo com os resultados, tem-se uma melhor estimativa de energia com a vazão de $60\left(\mathrm{~m}^{3} / \mathrm{s}\right)$ para turbina Francis. Porém, tal valor se afasta das médias de alguns meses como mostrado na Tab. 5. Usufruiria da eficiência das turbinas apenas no período chuvoso, ficando muito baixa a geração no período seco.

d) As diretrizes da Eletrobrás para projetos de PCH considera que a vazão deverá ser a mínima medida no local, ou $\mathrm{Q}_{95 \%}$, ou ainda, a vazão média ao longo do período crítico do sistema interligado, 44,6751 ( $\left.\mathrm{m}^{3} / \mathrm{s}\right)$. Considerando a afirmação acima e os resultados da tabela, a vazão escolhida que melhor se encaixa para essa estimativa de energia é de $45\left(\mathrm{~m}^{3} / \mathrm{s}\right)$. Mesmo sendo um valor abaixo das vazões que apresentaram melhor potencial, a energia média gerada pela vazão de $45\left(\mathrm{~m}^{3} / \mathrm{s}\right)$ é atratativa.

e) A região escolhida apresenta um potencial para aproveitamentos do tipo hidrelétrico bastante considerável, podendo ser uma região de estudos para a implantação de empreendimentos dessa natureza do ponto de vista hidrológico.

\section{CONCLUSÕES}

O estudo realizado neste trabalho objetivou a estimar a energia média gerada para uma $\mathrm{PCH}$, analisando a série histórica de vazões de uma bacia hidrográfica utilizando a hidrologia estatística para determinar a vazão de projeto. Através dos resultados encontrados observa-se que a aplicação da análise estastítica permite uma apreciação mais abrangente dos valores de vazão que podem ser aplicados para empreendimentos hidrelétricos e que a interpretação de seus dados podem amparar as tomadas de decisões que são necessárias nas etapas seguintes do projeto de uma PCH.

De uma forma geral, este trabalho contribuiu com alguns estudos e análises que podem dar subsídios a trabalhos futuros como, por exemplo, a escolha do melhor tipo de turbina para uma bacia hidrográfica conforme o arranjo do aproveitamento hidrelétrico, visto que neste trabalho levou-se em consideração apenas a variação dos valores de vazão.

\section{REFERÊNCIAS}

Collischonn, W. e Tassi, R. 2008. Introduzindo Hidrologia. Instituto de Pesquisa Hidraúlica. Universidade Federal do Rio Grande do Sul.

Eletrobrás, C. E. B. 2000. Diretrizes para Estudos e Projetos de Pequenas Centrais Hidrelétricas. Brasília.

Faria, F. 2011. Metodologia de Prospeção de Pequenas Centrais Hidrelétricas. Dissertação de Mestrado, Escola Politécnica, Universidade de São Paulo.

Junior, R. F. V., Pissara, T. C. T., Passos, A. O., Ramos, T. G. e Abdala, V. L. 2010. Diagnóstico das Áreas de Preservação Permanente na Bacia Hidrográfica do Rio Tijuco, Ituiutaba-MG, Utilizando Tecnologia SIG. Eng. Agríc., Jaboticabal, v.30, n.3, p.495-503.

Miranda, R. L. 2009. Regulação Técnica para se Obter Melhor Eficiência na Motorização de Pequenas Centrais Hidrelétricas No Brasil. Dissertação de Mestrado, Universidade Salvador.

Reis, A. A., Naghettini, M. e Melo, M. D. 2007. Estudo Comparativo, Aplicação e Definição de Metodologias Apropriadas para a Determinação da Vazão Ecológica na Bacia do Rio Pará, em Minas Gerais. XVII Simpósio Brasileiro de Recursos Hídricos.

Santos, B. B., Sobrinho, T. A. e Almeida, I. K. 2011. Avaliação da Disponibilidade Hídrica para Concessão de Outorgas Baseada em Vazões Mínimas de Referência. XIX Simpósio Brasileiro de Recursos Hídricos.

Sarmento, R. 2007. Termo de Referência para a Elaboração de Estudos Sobre a Vazão Ecológica na Bacia do Rio São Francisco. Edital n. 05 do ano de 2006, PROJETO 704BRA2041 da Organização das Nações Unidas para a Educação, a Ciência e a Cultura - UNESCO.

\section{RESPONSABILIDADE AUTORAL}

Os autores são os únicos responsáveis pelo conteúdo deste trabalho. 


\title{
ESTIMATE OF AVERAGE ENERGY GENERATED IN A WATERSHED BY STATISTICAL ANALYZES
}

\author{
Jacson Hudson Inácio Ferreira, Jacson@iftm.edu.br ${ }^{1}$ \\ José Roberto Camacho, jrcamacho@ufu.br ${ }^{1}$ \\ Juliana Almansa Malagoli, juliana.malagoni@gmail.com ${ }^{1}$ \\ ${ }^{1}$ Federal University of Uberlândia - Faculty of Electrical Engineering. \\ Av.: João Naves de Ávila, nº 2121, Bairro: Santa Mônica, CEP: 38.408-100, Uberlândia-MG, Brasil
}

\begin{abstract}
The estimate average energy generated is one of the important aspects analyzed during the first stage of the deployment of a small hydropower, the Estimate Hydroelectric Potential. In this scenario, knowledge of water availability is a fundamental part of the hydrological studies of a watershed, studies pertaining to the stage of the cycle to determine the flow of a river or precipitation in a location or region, including its temporal variability. For this it is necessary to use some statistical values that summarize, in large part, the hydrological behavior of the river or watershed. In this context, this work has the objective to perform a statistical analysis to determine the values of the variables that affect the calculation of the average energy: reference flow $Q_{7,10}$, the average monthly flows and the curve of stay. It was used the data from streamflow time series 1942-2013 of Ituiutaba fluviometric station located in the catchment area of the river Tijuco, in Minas Gerais. In the analysis of the variables, it was necessary to know and study the organs and state laws, a probabilistic model (Weibull distribution) and computational tools to help determine the values. It can be said that the calculation of the estimated average energy generated from the statistical analysis of the flow rate for the river Tijuco provided an attractive potential hydroelectric. It was also found that the statistical hydrology in the process of estimating the average power for hydroelectric projects provide reliable data and that the interpretation of the data can support the decision in the phase os projects.
\end{abstract}

Keywords: Hydrology Statistics, Flow, Estimate of Average Energy. 